\title{
Incidence, Clinicopathological Profile and Location- Based Outcome of Intracranial Meningiomas: 10-Year Institutional Study with Review of Literature
}

\author{
Feroze Ganai ${ }^{1}$ Humam Nisar Tanki ${ }^{1} \quad$ Afaq Sherwani ${ }^{1} \quad$ Kirmani Altaf $^{1} \quad$ Nazish Chisti ${ }^{1} \quad$ Altaf Ramzan $^{1}$ \\ ${ }^{1}$ Department of Neurosurgery and Surgery, Sheri Kashmir Institute \\ of Medical Sciences, Kashmir, Jammu \& Kashmir, India

\begin{abstract}
Address for correspondence Humam Nisar Tanki, MCh, Department of Neurosurgery, Sheri Kashmir Institute of Medical Sciences, Kashmir 190010, Jammu \& Kashmir, India (e-mail: humamtanki@yahoo.co.in).
\end{abstract}

Indian J Neurosurg 2021;1:42-48.

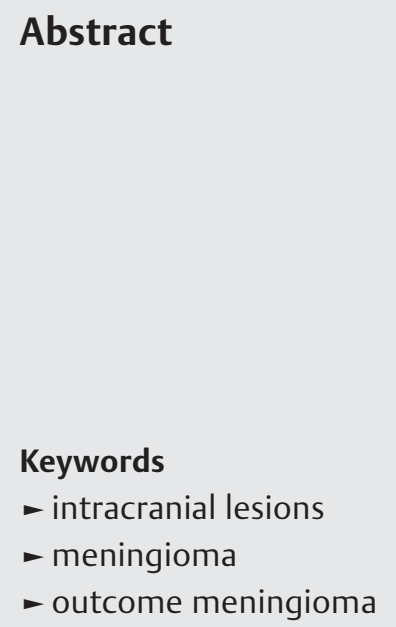

Intracranial meningiomas are the most common extra-axial tumors, representing $15 \%$ of all brain tumors. Arising from the arachnoid cells, and common in middle-aged women, $90 \%$ meningiomas are benign. We conducted a 10-year study on 183 cases of intracranial meningiomas and observed a lower and decreasing trend; the mean age was 43.3 years but there was also a significant incidence in young females. Parasagittal/ falx (29\%), sphenoid ridge, convexity meningiomas and middle cranial fossa locations were more common. Histopathologically, meningothelial meningioma was the most common. Benign (WHO I) tumors were found in above 90\%, atypical (WHO II) in $5 \%$ cases, and malignant (WHO III) in $<4 \%$ patients. Most patients underwent Simpsons Grade I excision (35.6\%) with dural reconstruction because of late presentations. Posterior fossa meningiomas were mostly benign, while intraventricular ones were mostly malignant with highest postoperation mortality. Mortality in operated patients was $9.8 \%$ but was highest in anterior fossa tumors (12.5\%).

\section{Introduction}

Meningiomas probably have affected humans since prehistoric times, as specimens of skulls from the Peruvian Andes have demonstrated the hyperostosis that can occur with such tumors. ${ }^{1}$ Arising from the arachnoid "Cap" cells of the arachnoid villi in the meninges, these tumors are usually benign in nature but can be malignant occasionally. ${ }^{2}$ Meningiomas account for over 30 percent of all primary brain tumors; it is twice as common in women as in men and usually occur in their 40 s to 50 s but can actually occur at any age. The annual incidence per 100,000 people ranges from two to seven for women and from one to five for men. ${ }^{3}$ As they grow, meningiomas compress adjacent brain tissue. Symptoms are often related to this compression of brain tissue or cranial nerves and venous sinuses or blood vessels. In some cases, meningioma growth can also extend into the bones of the skull and orbit and produce visible changes.

DOI https://doi.org/ $10.1055 / \mathrm{s}-0040-1714436$ ISSN 2277-954X.
Most cases of meningiomas are sporadic; however, radiation to the scalp may increase risk for developing meningiomas. ${ }^{4}$ The WHO classification divides meningiomas into the following three grades-Grade I: benign, Grade II: and typical, and Grade III: malignant (anaplastic). ${ }^{5}$

The profile of intracranial meningiomas was studied retrospectively and prospectively in the Department of Neurosurgery for a period of 10 years. Our purpose was to define the incidence, epidemiological and clinicopathological profile, postoperative survival/mortality, and outcome of intracranial meningioma patients.

\section{Materials and Methods}

This 10-year study included all the patients admitted to the Department of Neurosurgery with a provisional diagnosis of intracranial meningioma. Retrospectively, the case sheets were studied from July 2007 to July 2015 and prospectively

\footnotetext{
(c) 2020. Neurological Surgeons' Society of India.

This is an open access article published by Thieme under the terms of the Creative Commons Attribution-NonDerivative-NonCommercial-License, permitting copying and reproduction so long as the original work is given appropriate credit. Contents may not be used for commercial purposes, or adapted, remixed, transformed or built upon. (https://creativecommons.org/ licenses/by-nc-nd/4.0/)

Thieme Medical and Scientific Publishers Pvt. Ltd., A-12, 2nd Floor, Sector 2, Noida-201301 UP, India
} 
from August 2015 to July 2017 on admission and postoperative follow-up.

A detailed history and a thorough physical examination of each patient, including age, sex, residence, presenting complaints with emphasis on most incapacitating symptoms, evident neurodeficits and cognitive changes, was recorded. Baseline investigations and preanesthetic check were done. $\mathrm{X}$-ray skull, plain/contrast CT and MRI were conducted in every patient. Angiography in only select cases was advised, such as parasagittal meningioma where sinus infiltration is expected, or large skull base lesions to assess vascular supply, tumor encroachment on vessels or feasibility of embolization. Fundoscopy and audiometry was done in special cases or patients afflicted with impaired vision or defective hearing. Once the diagnosis of intracranial meningioma was established, most of the patients were candidates for surgery since surgery is the treatment of choice. For nonsurgical patients, the following exclusion criteria were: 1 ) incidental small lesions less than $3 \mathrm{~cm}$ without edema, especially in eloquent area, 2) small lesions with controllable seizures, $3)$ calcified lesions with smooth margins and a long history, 4 ) elderly (>70) and those with severe comorbidities having slowly progressive lesion. 5) refusal for treatment were excluded and managed expectantly, with serial imaging and follow-up. Every tissue specimen was sent for histopathological examination. Postoperatively, patients were monitored in the surgical intensive care unit for 2 to 5 days and later shifted to the neurosurgery ward. A CT brain check was done before the patient was discharged from hospital. After discharge, patients were followed at outpatient department (OPD) for a period of 6 months. Thereafter, data from patients was analyzed for the following variables to be studied: hospital-based incidence and prevalence, age/sex variations, most sensitive diagnostic tool, histological types, postoperative survival/mortality, and outcome of intracranial meningioma patients in comparison to other regions of world with extensive review of the literature.

Analysis was undertaken and the results were tabulated and analyzed for statistical significance. All the data were entered and tabulated in a MS Excel 2011 spreadsheet and analyzed using StatsDirect version 3 (StatsDirected Ltd, U.K.) statistical analysis software. Data was expressed using descriptive statistics in mean, simple frequencies for nonnumeric variables, simple average for numeric variables, and percentage for categorical variables.

\section{Results and Observations}

Our retroprospective study comprised 183 patients afflicted with intracranial meningiomas. Age of the patients varied between 9 to 75 years, but only four of them turned out to be children (2.1\%). The maximum number of patients belonged to the age group of 40 to 49 (52) years and 30 to 39 (50) years, respectively. The mean age of patients was 43.4 years and median age was 43 years. As many as 111 (61\%) patients were females and $72(39 \%)$ were males. The mean age for males was 45.6 years and 41.9 years for females. Sex ratio did not show any particular pattern in different age groups, although females were more than males in all age groups, except in $0-9$ years and $\geq 60$ years age groups.

The majority of patients $(146 ; 79.8 \%$ ) belonged to rural areas and $37(20.2 \%)$ were from urban areas. There were 17 males (9.3\%) from urban areas and 56 (30.6\%) from rural areas. There were 20 females from urban areas (10.9\%) and $90(49.1 \%)$ from rural areas, implying that almost half the study patients were females from rural areas. Population wise, $50.3 \%$ were housewives, $16.4 \%$ employees, $13.1 \%$ farmers, and $7.1 \%$ students in decreasing order, proving there is no correlation to profession or exposure to toxins.

Headache was the most common symptom seen in 98 patients (53.6\%), followed by seizures in 56 (30.6\%) patients, and the rest of the clinical features are represented in - Table 1. Surprisingly, the Glasgow Coma Scale (GCS) score was 15 in $86.8 \%$ and < 15 in only $13.1 \%$ patients at the time of admission (- Fig. 1).

As many as 39 patients had cranial nerve involvement, with the most common being optic nerve $(n=13)$ and olfactory nerve (10). Cranial nerves were involved in the following order: optic nerve $13>$ olfactory $10>$ trigeminal $7>$ vestibulocochlear $4>$ oculomotor $3>$ trochlear $=$ facial nerve $2>$ abducent nerve 1 , but no vagus, glossopharyngeal, accessory and hypoglossal nerves.

Anatomically, middle fossa meningiomas were the most common ones seen in 40 patients (21.9\%) followed by anterior fossa in $29(15.8 \%)$ and posterior fossa in $25(13.7 \%)$ patients. Various sites of meningiomas are depicted in $\boldsymbol{-}$ Table $\mathbf{2}$ and $\boldsymbol{\bullet}$ Fig. $\mathbf{2}$.

Table 1 Clinical presentation

\begin{tabular}{|c|c|}
\hline Symptoms/signs & $N(\%)$ \\
\hline \multicolumn{2}{|l|}{ Symptoms } \\
\hline Headache & $98(53.60 \%)$ \\
\hline Nausea and vomiting & $54(29.50 \%)$ \\
\hline Seizures & $56(30.60 \%)$ \\
\hline Visual changes & $50(27.30 \%)$ \\
\hline Weakness of limb/s & 37 (20.20\%) \\
\hline Behavioral changes & $32(17.50 \%)$ \\
\hline LOC & $23(12.60 \%)$ \\
\hline Gait disturbances & $18(9.80 \%)$ \\
\hline Speech impairment & $17(9.30 \%)$ \\
\hline Urinary incontinence & $14(7.70 \%)$ \\
\hline \multicolumn{2}{|l|}{ Signs/examination } \\
\hline $\begin{array}{l}\text { Level of consciousness } \\
(\mathrm{GCS}=)\end{array}$ & $\begin{array}{l}15=159 \text { pts, } 14=9,13=7 \\
12=4 \text { and GCS } 11,10, \\
9 \text { and } 8 \text { is } 1 \text { point each. }\end{array}$ \\
\hline Aphasia & $8(4.4 \%)$ \\
\hline Hemiplegia & $12(6.60 \%)$ \\
\hline Hemianesthesia & $4(2.20 \%)$ \\
\hline Hemianopsia & $10(5.50 \%)$ \\
\hline Cranial nerve involved & $39(21.30 \%)$ \\
\hline Cerebellar signs & $14(7.70 \%)$ \\
\hline Memory changes & 37 (20.20\%) \\
\hline
\end{tabular}

Abbreviations: GCS, Glasgow Coma Scale; LOC, level of consciousness. 


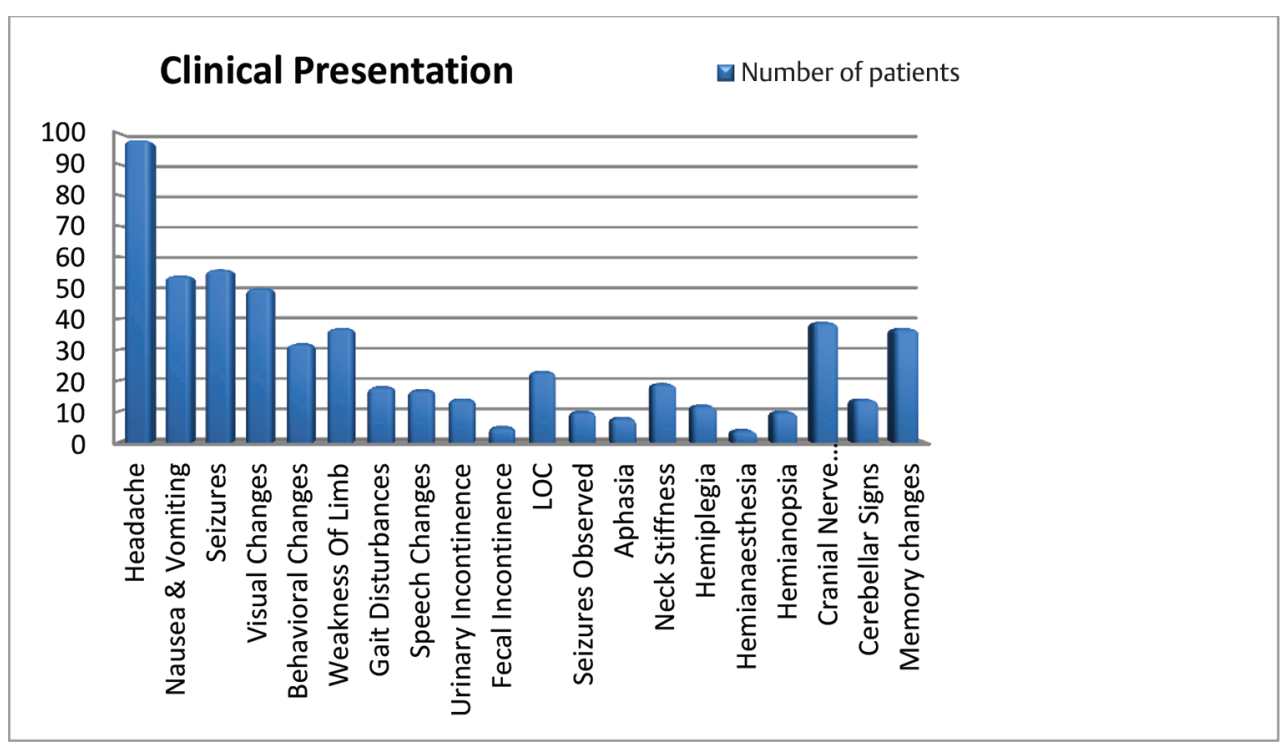

Fig. 1 Symptoms and signs of meningiomas.

Table 2 Distribution of different grades (WHO I-III) of meningiomas in relation to anatomical location of the tumor

\begin{tabular}{|c|c|c|c|c|c|c|}
\hline Intracranial meningiomas & Meningioma location & $n$ & $\%$ & Benign & Atypical & Malignant \\
\hline \multirow{2}{*}{$\begin{array}{l}\text { Anterior fossa } \\
29(15.8 \%)\end{array}$} & Olfactory groove meningioma & 17 & 9.3 & $82.3 \%$ & $11.7 \%$ & 6 \\
\hline & Tuberculum sellae meningioma & 12 & 6.6 & $91.7 \%$ & $8.3 \%$ & $0 \%$ \\
\hline \multirow{2}{*}{$\begin{array}{l}\text { Middle fossa } \\
40(21.9 \%)\end{array}$} & Sphenoid ridge meningioma & 36 & 19.7 & $94.1 \%$ & $2.9 \%$ & $2.9 \%$ \\
\hline & Cavernous Sinus Meningioma & 4 & 2.2 & $100 \%$ & 0 & 0 \\
\hline \multirow{5}{*}{$\begin{array}{l}\text { Posterior fossa } \\
25(13.7 \%)\end{array}$} & CP angle meningioma & 5 & 2.7 & $100 \%$ & 0 & 0 \\
\hline & Petroclival meningioma & 8 & 4.4 & $83.3 \%$ & 0 & $16.7 \%$ \\
\hline & Foramen magnum meningioma & 1 & 0.5 & $100 \%$ & 0 & 0 \\
\hline & Peritorcular meningioma & 2 & 1.1 & $100 \%$ & 0 & 0 \\
\hline & Tentorial meningioma & 9 & 4.9 & $100 \%$ & 0 & 0 \\
\hline \multicolumn{2}{|l|}{ Parasagittal meningioma } & 31 & 16.9 & $96.7 \%$ & $3.3 \%$ & $0 \%$ \\
\hline \multicolumn{2}{|l|}{ Parafalcine meningioma } & 22 & 12.0 & $90.9 \%$ & $0 \%$ & $9.9 \%$ \\
\hline \multicolumn{2}{|l|}{ Convexity meningioma } & 28 & 15.3 & $89.3 \%$ & $10.7 \%$ & $0 \%$ \\
\hline \multicolumn{2}{|l|}{ Intraventricular meningioma } & 6 & 3.3 & $75 \%$ & $0 \%$ & $25 \%$ \\
\hline \multicolumn{2}{|l|}{ Intraorbital meningioma } & 2 & 1.1 & $100 \%$ & 0 & 0 \\
\hline
\end{tabular}

Abbreviation: $\mathrm{CP}$, cerebellopontine.

Sensitivity of MRI was greater than CT, as CT was indicative of meningioma in 158 (86.3\%) cases while MRI scored in 168 (91.8\%) cases. The characteristic feature is that of increasing tumor blush throughout the course of the arterial phase, persisting well into the late venous phase with slow washout. MRI had greater sensitivity in expressing characteristics such as extra-axial location of tumor, hyperostosis, tumor capsule, dural tail, mass effects of tumor on brain parenchyma and homogeneous contrast enhancement, while CT was more sensitive in detecting calcification and intense contrast enhancement.

Except for nine patients, the rest were operated for tumor. In five patients with hydrocephalus, cerebrospinal fluid (CSF) diversion by shunt was done, and four patients who were observed regularly for tumor progression did not require surgery. Dural reconstruction was needed in 111 (63.8\%) patients among those operated upon. Skull bone involvement was seen only in four patients, temporal in two, sphenoid in one, and occipital bone in one patient. Simpsons Grade I excision was performed in 62 patients (35.6\%), Grade II excision in five patients (33.3\%), Grade III excision in 33 patients (19\%), Grade IV in 18 patients (10.3\%) and Grade $V$ excision or simple decompression with biopsy was done in only four patients (2.3\%).

Based on histopathology there are 15 variants ${ }^{6}$ of meningiomas. All the 15 types were observed in our study (-Table 3 ), with the most common being meningothelial meningioma in 105 patients (60.3\%). Benign or WHO Grade I tumors formed the largest group 160 (92\%), eight patients (4.6\%) had atypical (WHO Grade II) tumors, and only six (3.4\%) had malignant (WHO Grade III) tumors.

- Table 2 depicts distribution of different grades (WHO I-III) of meningiomas in relation to anatomical location of the tumor. There were only two cases of intraorbital meningioma and both were benign (100\%). Out of 183 patients, 


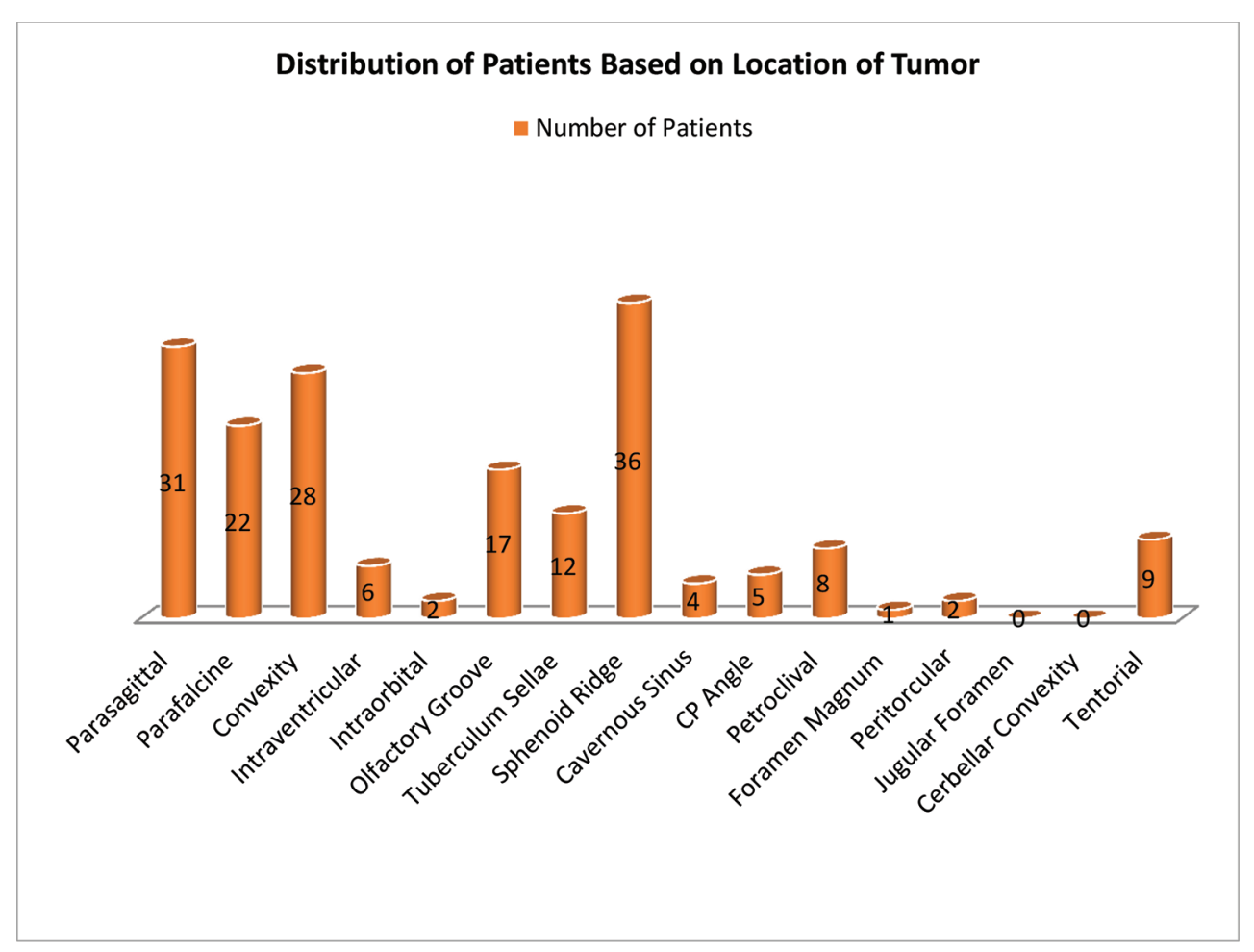

Fig. 2 Distribution of patients based on the tumor location.

Table 3 Distribution of patients based on histopathological examination

\begin{tabular}{|c|c|c|c|c|}
\hline Type & $N$ & $\%$ & $\begin{array}{l}\text { WHO } \\
\text { Grade }\end{array}$ & $\begin{array}{l}N \\
(\%)\end{array}$ \\
\hline $\begin{array}{l}\text { Meningothelial } \\
\text { meningioma }\end{array}$ & 105 & 60.3 & 1 & \multirow[t]{9}{*}{$\begin{array}{l}160 \\
(92 \%)\end{array}$} \\
\hline $\begin{array}{l}\text { Fibroblastic } \\
\text { meningioma }\end{array}$ & 20 & 11.5 & 1 & \\
\hline $\begin{array}{l}\text { Transitional } \\
\text { meningioma }\end{array}$ & 20 & 11.5 & 1 & \\
\hline $\begin{array}{l}\text { Psammomatous } \\
\text { meningioma }\end{array}$ & 5 & 2.9 & 1 & \\
\hline $\begin{array}{l}\text { Microcystic } \\
\text { meningioma }\end{array}$ & 1 & 0.6 & 1 & \\
\hline $\begin{array}{l}\text { Secretory } \\
\text { meningioma }\end{array}$ & 3 & 1.7 & 1 & \\
\hline $\begin{array}{l}\text { Angiomatous } \\
\text { meningioma }\end{array}$ & 3 & 1.7 & 1 & \\
\hline $\begin{array}{l}\text { Lymphoplasmocytic } \\
\text { meningioma }\end{array}$ & 2 & 1.1 & 1 & \\
\hline $\begin{array}{l}\text { Metaplastic } \\
\text { meningioma }\end{array}$ & 1 & 0.6 & 1 & \\
\hline $\begin{array}{l}\text { Clear cell } \\
\text { meningioma }\end{array}$ & 2 & 1.1 & ॥ & \multirow[t]{3}{*}{$\begin{array}{l}8 \\
(4.6 \%)\end{array}$} \\
\hline $\begin{array}{l}\text { Chordoid } \\
\text { meningioma }\end{array}$ & 2 & 1.1 & II & \\
\hline Atypical meningioma & 4 & 2.3 & II & \\
\hline Papillary meningioma & 1 & 0.6 & III & \multirow{2}{*}{$\begin{array}{l}6 \\
(3.4 \%)\end{array}$} \\
\hline $\begin{array}{l}\text { Rhabdoid } \\
\text { meningioma }\end{array}$ & 3 & & & \\
\hline
\end{tabular}

Table 4 Postoperative mortality based on location of meningioma

\begin{tabular}{|l|l|l|l|}
\hline Location & $\begin{array}{l}\text { Operated } \\
\text { patients }\end{array}$ & Dead & Mortality \\
\hline Parasagittal/parafalcine & 52 & 4 & $7.7 \%$ \\
\hline Convexity & 28 & 3 & $10.7 \%$ \\
\hline Intraventricular & 4 & 1 & $25.0 \%$ \\
\hline Intraorbital & 2 & 0 & $0.0 \%$ \\
\hline Olfactory groove & 17 & 2 & $11.8 \%$ \\
\hline Tuberculum sellae & 12 & 2 & $16.7 \%$ \\
\hline Sphenoid ridge & 34 & 2 & $5.9 \%$ \\
\hline Cavernous sinus & 4 & 0 & $0.0 \%$ \\
\hline Posterior fossa & 21 & 3 & $14.3 \%$ \\
\hline
\end{tabular}

19 (10.4\%) died during hospital stay and 164 (89.6\%) were discharged. Among operated patients, 17 died after surgery in the postoperative period; survival in operated patients was $90.2 \%$ and mortality $9.8 \%$. Table 4 depicts the location-wise mortality rates.

Maximum postoperative mortality of $25 \%$ was seen in intraventricular meningioma patients. Among 160 benign (WHO I) meningiomas, 13 died (8.1\%). Two out of 8 (25\%) patients died among those afflicted with atypical (WHO II) tumors, and $33.3 \%$ with malignant (WHO III) tumors died postoperatively. Among 111 females, 10 (11\%) died and among 72 males, 9 (12.5\%) died. Maximum mortality was observed in age group $0-9$ years (100\%) and age $\geq 60$ years (18.5\%). 


\section{Discussion}

In 1922, Cushing coined the term meningioma to describe tumors originating from the meninges. ${ }^{7}$ In 1957, Simpson reported a method of grading operations for meningiomas. ${ }^{8}$ Meningiomas are the second most common primary neoplasm of the central nervous system (CNS). ${ }^{1}$ These tumors are usually benign in nature; however, they can be malignant. ${ }^{2}$ Recurrence rate varies with grade and length of follow-up: WHO I meningioma: 6.9\%,WHO II (atypical) meningioma: $34.6 \%$, and WHO III (malignant) meningioma: $72.7 \%$.

In our study, the number of brain tumors admitted in 10 years was 1238 , of which 183 (15\%) were meningiomas. A similar 26-year study had seen incidence of meningiomas to be $17.4 \%$ and prevalence $6.7 / 0.1$ million (Bhat et al), ${ }^{9}$ with similar incidence seen in other studies as well. ${ }^{10,11}$ Crude incidence was $0.32 / 0.1$ million population per year; males were $0.11 / 0.1$ million men population per year and females 0.21/0.1 million, with prevalence being 2.61/0.1 million population. Data from the Central Brain Tumor Registry U.S. revealed an age-adjusted incidence rate (per 100,000 individuals) of 5.04 and 2.46 for females and males, respectively. ${ }^{10,11}$ Longsfreth et $\mathrm{al}^{3}$ in a 30-year analytical study across the globe, including Europe, USA and Canada, found the incidence of 1.1/0.1 million in men and 2.2/0.1 million in women. Incidence and prevalence of meningiomas in Kashmir was found to be lesser, signifying that incidence in this Asian region is lower than other continents and is decreasing with time.

Mean age of our patients was 43.4 years and median age 43 years. Age group 30 to 39 years and 40 to 49 years constituted $27.3 \%$ and $28.4 \%$ of patients, respectively, and represented the two largest groups. Similar age trends is supported by most of the studies, ${ }^{10,12}$ with maximum patients in the $40-50$ years age group and mean age of patients being 47.5 years, but few studies had prevalence in the $50-60$ years age group. ${ }^{10}$ As much as $61 \%$ of the our patients were females and $39 \%$ males, with female:male (F:M) ratio of $1.56: 1$. In most of literature, this ratio ranges between $1.5: 1$ to $2: 1 .^{12}$ We also observed that F:M ratio in the age group 20-29 years was 4:1, suggesting that incidence is four times higher in young females.

Presenting symptoms and signs in decreasing order of frequency were headache (53.6\%), seizures (30.6\%), nausea and vomiting (29.5\%), visual changes (27.3\%), cranial nerve involvement (21.3\%), weakness of limb (20.2\%), memory changes (20.2\%), behavioral changes (17.5\%), impaired consciousness (12.6\%), gait disturbances (9.8\%), speech changes $(9.3 \%)$, urinary incontinence $(7.7 \%)$, cerebellar signs (7.7\%), and hemianesthesia (2.2\%). These findings were consistent with other studies, as all reported headache (36-67.3\%), seizures (34-40\%) and visual impairment (16-38.5\%) as most common symptoms. ${ }^{13,14}$

Based on anatomical location, meningiomas were located at anterior fossa in 29 (15.8\%), middle fossa in 40 (21.9\%), and posterior fossa in 25 (13.7\%) patients. In anterior fossa, olfactory groove and tuberculum sellae were the most frequent

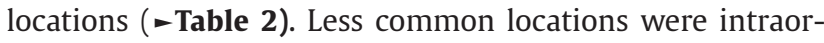
bital in two (1.1\%), peritorcular in two (1.1\%) and foramen magnum meningioma in one ( $0.5 \%)$. We observed that in each study, the most-common locations are not similar. In our study, the three most common sites were parasagittal/falx in $29 \%$, sphenoid wing in $19.7 \%$, and convexity in $15.3 \%$. Yao et $\mathrm{ll}^{15}$ had parasagittal/falx (35\%), cerebral convexity (19.3\%) and sphenoid wing (10.2\%) out of 615 cases, while Mezue et $\mathrm{al}^{14}$ reported the most common locations as olfactory groove (26.9\%), convexity (21.2\%), parasagittal/falx (19.2\%), and sphenoid ridge (15.4\%). Posterior fossa meningiomas in our cases constituted 25 (13.7\%) patients formed by tentorial $36 \%$, petroclival $32 \%$, cerebellopontine (CP) angle $20 \%$ and foramen magnum $4 \%$, while Dumitrescu et $\mathrm{al}^{16}$ reported CP angle in $48.5 \%$, petroclival in $11.4 \%$ and foramen magnum in $8.5 \%$, but $17.1 \%$ had giant tumors with broad attachment at the tentorium. We had nine tentorial meningiomas, with most (6) having supratentorial extension, but a majority of the studies had tentorial meningiomas with mostly infratentorial extension. ${ }^{17}$

Plain skull images may demonstrate calcification in meningiomas of the skull base or convexity. In some cases, meningioma growth can also extend into the bones of the head and face, which may produce visible changes. The sensitivity and specificity of MRI is highest in the diagnosis of meningiomas. ${ }^{18} \mathrm{X}$-ray skull suggested meningioma in four patients, out of which three patients showed calcification and one case showed calcification and widening of sutures. Contrast MRI brain was more sensitive (sensitivity 91.8\%) compared with CT, having sensitivity of $86.3 \%$. These findings are consistent with the findings of other studies also. ${ }^{18}$ MRI better defined the extra-axial location of tumor, hyperostosis, tumor capsule, dural tail, mass effects of tumor on brain parenchyma and homogeneous contrast enhancement, while CT was better in detecting calcification and intense contrast enhancement. ${ }^{18}$

Out of 183 patients, 174 (95\%) were operated for tumor decompression, five were managed with palliative CSF diversion, and four patients were not operated but observed. Dural reconstruction was done in $63.8 \%$ of the patients. Only four (2.2\%) had bone involvement, two had parasagittal, one had sphenoid wing, and one had cavernous sinus meningioma, and all of them were females. Bone involvement is a rare manifestation of meningiomas. It particularly occurs in atypical and malignant meningiomas and suggests poorer outcome. Drevelegas ${ }^{19}$ described involvement of bone in 3\% cases, which is consistent with the results in our study. Patients in our study were referred for fractionated radiotherapy within the hospital or stereotactic radiosurgery to higher centers, if they had such facilities in place: 1) after surgery for malignant meningiomas, (2) following incomplete resection with high risks for reoperation, (3) multiple recurrent tumors, and (4) inoperable cases like some cases of cavernous sinus or clival meningiomas. Chemotherapy and hormonal therapy have not yet been incorporated in our treatment protocol, as there is no convincing evidence regarding their success in literature to date.

Simpson $^{8}$ published his hallmark paper in 1957, showing a significant correlation between degree of meningioma resection and tumor recurrence. Simpsons Grade I excision 
was performed in 62 (35.6\%) patients, Grade II excision in 58 (33.3\%), Grade III excision in 19\%, and Grade IV excision in $10 \%$ patients. Simpsons V excision or simple decompression with biopsy was done in only four $(2.3 \%)$ patients. These results differ from other studies, as Simpsons Grade II excision is most commonly performed..$^{9}$ Our hypothesis was that majority of our patients belonged to the poor economic and educational status, with limited access to tertiary care services; hence, most often patients presented very late when tumor had grown to a significant size and started involving dura or even bone, a stage when signs and symptoms become very evident and patient feels the need to seek medical help. Comparatively, in developed nations, patients are diagnosed very early, before dural or significant bony involvement.

Histologically, meningiomas are classified into 15 types. ${ }^{6}$ Meningothelial meningioma was the most common variant present in $60.3 \%$, followed by fibroblastic and transitional meningioma in $11.5 \%$ patients each. Yao ${ }^{15}$ found meningothelial in (41\%), transitional (24.9\%), fibroblastic (18.7\%), atypical (7.4\%), and anaplastic (2.8\%). Incidence of histological variants seemed to differ in each study. Perry et a ${ }^{20}$ observed meningothelial (63.5\%) and transitional meningiomas $(22.1 \%)$ to be most common histological types.

WHO classifies meningiomas into the following: typical or benign (88-94\%), atypical (5-7\%), and anaplastic or malignant $(1-2 \%)$. ${ }^{5,18}$ WHO Grade I tumors in our study constituted $92 \%$, while WHO II and WHO III composed $4.6 \%$ and $3.4 \%$ of patients, respectively, which were percentages in concordance with other studies.,13,18 Helseth et al studied 1632 cases and found $95 \%$ were histologically benign. ${ }^{21}$

Out of 183 patients, 19 patients (operated and nonoperated) died during the hospital stay and 164 were discharged. Mortality in operated patients was $9.8 \%(n=17)$ which was slightly higher than some other studies (1.8\% and 3.5\%). ${ }^{14,22}$ The reason was that most patients presented very late neurological deterioration, or when tumor had grown to large sizes, leading to higher surgical risk and poorer outcome. Surprisingly, the mortality was $13.7 \%$ and $12 \%$ in anterior and posterior fossa operated cases, respectively, likely due to giant size with delayed clinical signs in anterior fossa tumors. Mortality in females (9\%) was lower than males (12.5\%), while in patients above 60 it was high (18.5\%).

Finally, we concluded that intracranial meningiomas comprise $15 \%$ of all brain tumors but the incidence is lower and shows a decreasing trend yearly; mean age was 43.3 years, common in females but four times more common in young females (aged below 30 years) than males. Headache (53.6\%) and seizures (30.6\%) were the most common presentations. Parasagittal/falx (29\%), sphenoid ridge (19.7\%) and convexity meningiomas (15.3\%) and middle cranial fossa lesions were most common.

Contrast MRI is the most sensitive diagnostic tool (91.8\% sensitivity) tool and also provides most detailed definitions of tumor. Angiography may be needed in select cases. Histopathologically, meningothelial meningioma (60.3\%) is the most common type followed by fibroblastic and transitional meningioma. Benign (WHO I) tumors were found in greater than $90 \%$ patients, atypical (WHO II) in 5\% and malignant (WHO III) in < 4\% of patients. Most patients underwent Simpsons Grade I excision (35.6\%) with dural reconstruction (more than 60\%) because of late presentations as most tumors were large and involved bone and dura. Posterior fossa meningiomas were mostly benign, while intraventricular were mostly malignant (100\%) pathologically with high postop mortality. Mortality in operated patients was $9.8 \%$ but was highest in anterior fossa tumors (12.5\%) because of delayed presentation and subtle signs but lesser in middle and posterior fossa tumors. Mortality was lower in females and in patients below 60 years of age.

\section{Conflict of Interest}

None declared.

\section{References}

1 Buetow MP, Buetow PC, Smirniotopoulos JG. Typical, atypical, and misleading features in meningioma. Radiographics 1991;11(6):1087-1106

2 Goldsmith BJ, Wara WM, Wilson CB, Larson DA. Postoperative irradiation for subtotally resected meningiomas. A retrospective analysis of 140 patients treated from 1967 to 1990. J Neurosurg 1994;80(2):195-201

3 Longstreth WT, Jr, Dennis LK, McGuire VM, Drangsholt MT, Koepsell TD. Epidemiology of intracranial meningioma. Cancer 1993;72(3):639-648

4 Rabin BM, MeyerJR, BerlinJW, Marymount MH, Palka PS, Russell EJ. Radiation-induced changes in the central nervous system and head and neck. Radiographics 1996;16(5):1055-1072

5 Wrobel G, Roerig P, Kokocinski F, et al. Microarray-based gene expression profiling of benign, atypical and anaplastic meningiomas identifies novel genes associated with meningioma progression. Int J Cancer 2005;114(2):249-256

6 Riemenschneider MJ, Perry A, Reifenberger G. Histological classification and molecular genetics of meningiomas. Lancet Neurol 2006;5(12):1045-1054

7 Charbel FT, Hyun H, Misra M, Gueyikian S, Mafee RF. Juxtaorbital en plaque meningiomas. Report of four cases and review of literature. Radiol Clin North Am 1999;37(1):89-100, x

8 Simpson D. The recurrence of intracranial meningiomas after surgical treatment. J Neurol Neurosurg Psychiatry 1957;20(1):22-39

9 Bhat AR, Kirmani AR, Raina TH, et al. Analysis of surgical outcome of brain tumors in Kashmir - A 26 year experience at SKIMS. Journal of Medical Sciences 2008;11:152-158

10 Claus EB, Bondy ML, Schildkraut JM, Wiemels JL, Wrensch M, Black PM. Epidemiology of intracranial meningioma. Neurosurgery 2005;57(6):1088-1095, discussion 1088-1095

11 Klaeboe L, Lonn S, Scheie D, et al. Incidence of intracranial meningiomas in Denmark, Finland, Norway and Sweden, 1968-1997. Int J Cancer 2005;117(6):996-1001

12 Rohringer M, Sutherland GR, Louw DF, Sima AA. Incidence and clinicopathological features of meningioma. J Neurosurg 1989;71(5 Pt 1):665-672

13 Rockhill J, Mrugala M, Chamberlain MC. Intracranial meningiomas: an overview of diagnosis and treatment. Neurosurg Focus 2007;23(4):E1

14 Mezue WC, Ohaegbulam SC, Ndubuisi CA, Chikani MC, Achebe DS. Management of intracranial meningiomas in Enugu, Nigeria. Surg Neurol Int 2012;3:110 
15 Yao YT. Clinicopathologic analysis of 615 cases of meningioma with special reference to recurrence. J Formos Med Assoc 1994;93(2):145-152

16 Dumitrescu GF, Indrei A, Husseini ME, et al. Posterior fossa meningiomas: Correlation between site of origin and pathology. Romanian Neurosurgery 2010;3:327-338

17 Barrows HS, Harter DH. Tentorial meningiomas. J Neurol Neurosurg Psychiatry 1962;25(1):40-44

18 Castillo GC et al. Imaging in Brain Meningioma. eMedicine; 2004. Available at: http://www.emedicine.com/ped/topic3023.htm

19 Drevelegas A. Extra-axial brain tumors. Eur Radiol 2005;15(3): 453-467
20 Perry A, Scheithauer BW, Stafford SL, Lohse CM, Wollan PC. "Malignancy" in meningiomas: a clinicopathologic study of 116 patients, with grading implications. Cancer 1999;85(9): 2046-2056

21 Helseth A, Mørk SJ, Johansen A, Tretli S. Neoplasms of the central nervous system in Norway. IV. A population-based epidemiological study of meningiomas. APMIS 1989;97(7):646-654

22 Curry WT, McDermott MW, Carter BS. Barker FG II. Craniotomy for meningioma in the United States between 1988 and 2000: decreasing rate of mortality and the effect of provider caseload. J Neurosurg 2005;102(6):977-986 